\title{
MODELING LONG-TERM BEACH CHANGE UNDER INTERACTING LONGSHORE AND CROSS-SHORE PROCESSES
}

\begin{abstract}
Hans Hanson ${ }^{1}$, Magnus Larson², and Nicholas C. Kraus ${ }^{3}$
This paper presents mathematical formulations and a new numerical model GenCade that simulates beach and dune change in response to cross-shore processes of dune growth by wind and dune erosion by storms, and by gradients in longshore sand transport that will also alter shoreline position. The berm plays a central role since the potential for sand to be transported to the dune by wind depends on berm width, and sand lost in erosion of the dune during storms will widen the berm. Morphologic equilibrium considerations are introduced to improve reliability of predictions and stability of the non-linear model. An analytical solution is given to illustrate properties of the model under simplified conditions. Sensitivity tests with the numerical solution of the coupled equations demonstrate model performance. Finally, the numerical model is applied to examine the consequences of groin shortening at Westhampton Beach, Long Island, New York, as an alternative for providing a sand supply to the down-drift beach. Results indicate that the sand will be released over several decades as the shoreline and dune move landward in adjustment to the new equilibrium condition with the shortened groins.
\end{abstract}

Keywords: dune erosion, shoreline change, coastal evolution, numerical model, GenCade, Westhampton Beach

\section{INTRODUCTION}

Increasing societal and ecological demands on our coastal areas, together with a growing awareness of the risks of an anticipated long-term climatic change, have emphasized the need for morphological modeling capabilities that span decades to centuries. Such predictive technology would encompass regional trends and processes, storms, and multiple interacting coastal engineering projects of various kinds. The need for filling the gap between the local and regional scale models is becoming increasingly important as engineers are required to calculate for longer time spans, larger coastal extents, more complex conditions of the shore, and numerous engineering alternatives. Sediment must be managed on regional scales (longshore processes) as well as accounting for typical and more severe storms with climate change and rising sea level (cross-shore processes).

Coastal management requires quantitative predictive capability that represents episodic erosion by storms, dune build-up by wind, and long-term change produced by gradients in longshore sand transport. Regional processes such as shadowing by adjacent large land masses and sand storage and transfer at inlets also exert control of beach change at the project scale (Larson et al., 2002a; 2002b). Realistic representation of such processes therefore requires their mathematical descriptions and associated numerical modeling on several spatial and temporal scales. The interaction between waves, structures, and morphological processes must be described, but within a scheme that is compatible with boundary conditions and processes at regional scale. Also, model robustness and reliability must be assured by introducing equilibrium concepts towards which evolution is striving rather than using an open-ended modeling system of non-linear coupled processes.

This paper presents a theory for calculating beach and dune change through coupled storm and longer term or typical longshore processes. Change in the location of the dune toe, berm width, and shoreline position are calculated, while maintaining longshore transport rates representative of the regional long-term behavior of the coast. The paper begins with an introduction to and representation of dune evolution, which is then connected to longshore transport processes as represented in one-line models such as GENESIS (Hanson, 1989; Hanson and Kraus, 1989).

\section{REPRESENTATION OF DUNE EVOLUTION PROCESSES}

Dunes are formed by wind-blown sand transport from the berm and foreshore. Psuty (1990) discusses dune transformation processes for the general area of Long Island, NY, that enters the case study below. The berm refers to the mildly seaward sloping, nearly-horizontal portion of the sub-aerial beach seaward of the dune. The portion of the beach regularly exposed to waves in the swash zone, sloping downwards towards the still-water shoreline, is referred to as the foreshore. Fig. 1 is a definition sketch introducing beach morphology terminology and notation employed. In the present work, the subaqueous part of the profile is described by an equilibrium shape according to Dean (1977). Gradients in longshore transport are assumed to act upon the profile from berm crest $\left(y_{B}\right)$ to depth of closure $\left(y_{c}\right)$.

\footnotetext{
${ }^{1}$ Dept. of Water Resources Engineering, Lund University, S-22100 Lund, Sweden. Hans.Hanson@tvrl.Ith.se

2 Dept. of Water Resources Engineering, Lund University, S-22100 Lund, Sweden. Magnus.Larson@tvrl.Ith.se

${ }^{3}$ U.S. Army Engineer Res. \& Development Center, Coastal \& Hydraulics Lab., 3909 Halls Ferry Road, Vicksburg, MS 39180, USA. Nicholas.C.Kraus@usace.army.mil
} 


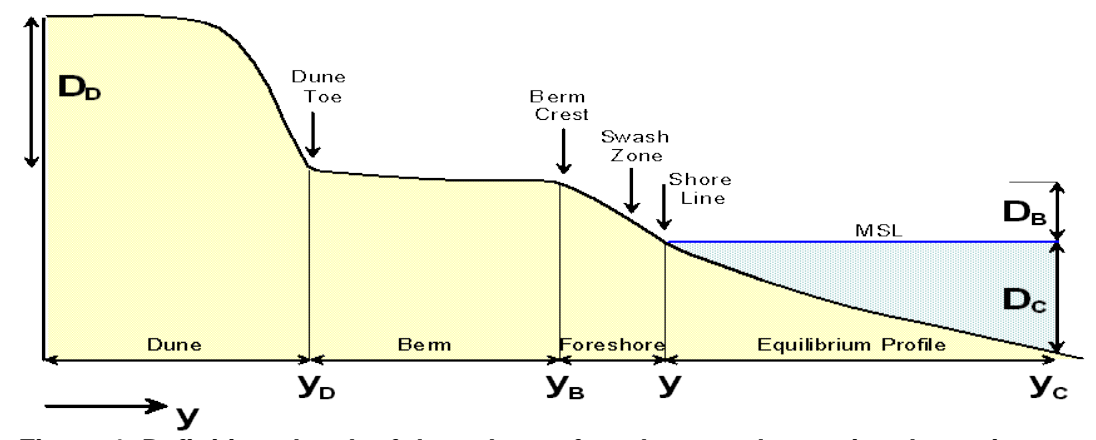

Figure 1. Definition sketch of dune, berm, foreshore, and associated notation.

Waves approaching the beach during high water level may attack the dune during storms, causing erosion and recession of the dune line. Sand released from the eroded dune supplies the beach with material that can be deposited offshore, especially during long-duration storms. Larson and Kraus (1991) examined storm-induced beach change for differing durations of storm surge with the SBEACH model (Larson and Kraus, 1989) and found that dune erosion by wave attack depend on berm width, with wider berm provides increased protection for the dune against wave attack. Build-up of dunes by wind-blown sand transport also depends on berm width (Hotta, 1984), for which a larger width promotes transport by wind. Hotta (1984) showed that, in his studies, a certain distance, about $10 \mathrm{~m}$, was required for transport by wind to become fully developed. This section describes a new theory that allows for numerical modeling of the interaction between the dune and the berm, including consequences for shoreline evolution.

\section{Dune Build-up by Wind}

It is assumed that a dune grows by sand blown landward from the berm, which, in turn, exchanges material with the foreshore and the underwater profile. A one-dimensional sand conservation equation for the dune volume growth by wind-blown transport, assuming that all the blown sand is trapped by the dune, is:

$$
\frac{d V_{D w}}{d t}=q_{w}
$$

where $V_{D w}$ is the dune volume (subscript $w$ refers wind), $t$ is time, and $q_{w}$ is the onshore sand transport by wind. If the dune height $D_{D}$ above the berm elevation remains constant during growth together with the dune shape, the seaward movement of the dune toe $\square y_{D w}$ for a given increase in dune volume $\square V_{D w}$ is:

$$
\Delta y_{D w}=\frac{\Delta V_{D w}}{D_{D}}
$$

It is assumed that sand transport to the dune is related to the width of the berm up to some distance over which equilibrium conditions have developed, , implying that beyond equilibrium a wider beach does not generate more transport by wind, (Davidson-Arnott and Law, 1990; Davidson-Arnott et al., 2005; see recent review of wind-blown sand transport prediction by Hopf and Sherman, 2007). A simple equation that exhibits these properties, with a slow but gradual increase of the transport rate by wind with beach width for narrow beaches, a stronger increase for wider beaches, and an upper limit that is approached gradually for wide beaches, while at the same time providing a continuous description of the transport with changes in berm width, is,

$$
q_{w}=q_{w o}\left(1-0.5\left(1-\tanh \left[\frac{\pi}{q_{\text {grad }}}\left(y_{B}-y_{D}-y_{50}\right)\right]\right)\right)
$$


where $q_{\text {wo }}$ is the maximum transport by wind for an infinitely wide beach, dependent on water and sand properties, $y_{B}$ and $y_{D}$ are the distances to the seaward end of the berm and the dune toe, respectively (see Fig. 1), with the $y$-axis pointing offshore, $y_{50}$ is the distance from the seaward end of the berm to where the wind-blown transport has reached $50 \%$ of its maximum, and $q_{\text {grad }}$ is the transport gradient at $y_{50}$. Bagnold (1954) suggested the transport rate relationship $q_{w o}=K_{w} u_{*}^{3} / g$, where $u_{*}$ is the wind shear velocity, $g$ is the acceleration due to gravity, and $K_{w}$ is an empirical coefficient that quantifies the influence of sand properties on the transport rate. Equation (3) describes a dune that advances towards the berm crest, although the rate of advance will decrease with time as the berm width decreases.

\section{Erosion by Wave Impact}

During storms, waves may strike and erode the dune during high water level. Denoting the erosion of the dune due to wave impact as $q_{o}$, the associated dune volume change (loss) $\square V_{D o}$ during a small time $\square t$ yields:

$$
\frac{d V_{D o}}{d t}=-q_{o}
$$

It is assumed that no overwash occurs and that the dune is not completely eroded (i.e., no breaching). The erosion rate due to dune impact by waves may be estimated as (Larson et al., 2004):

$$
q_{o}=4 C_{s} \frac{\left(R+\Delta h-z_{D}\right)^{2}}{T}, \quad R>z_{D}-\Delta h
$$

where $R$ is the run-up height (including setup) estimated from $R=a \sqrt{H_{o} L_{o}}$, in which $H_{o}$ is the deepwater root-mean-square wave height, $L_{o}$ is the deepwater wavelength, and $a$ is a coefficient (about 0.15 , which corresponds to a representative foreshore slope); $\square h$ is the surge level (including tide elevation relative to mean sea level (MSL)); $z_{D}$ is the dune toe elevation (with respect to MSL); $T$ is the swash period (taken to be the same as the wave period); and $C_{s}$ is an empirical coefficient. In the numerical implementation, $q_{o}$ varies at each time step and is computed following Eq. (5) from the input time series of waves.

Equation (5) is derived based on the wave impact on the dune, where the speed of the wave striking the dune is a key parameter (estimated through $R$ ). If there is a wide berm in front of the dune, the up-rushing wave may lose energy as it travels across the berm and strike the dune with less speed, causing less impact and erosion. Such an energy loss is not included in Eq, (5). In this study, a ballistics approach was taken to describe the front speed of the wave affected by friction as it propagates towards the dune face (Erikson et al., 2005). The governing equation for the wave front speed is:

$$
\frac{d u_{o}}{d t}=-k_{f} u_{o}^{2}
$$

where $u_{o}$ is the front speed and $k_{f}$ a friction coefficient. Rewriting Eq. (6) in terms of a coordinate $s$ along the berm, originating at the berm crest and pointing onshore, yields (note that $\left.d u_{o} / d t=u_{o} d u_{o} / d s\right)$ :

$$
u_{o} \frac{d u_{o}}{d s}=-k_{f} u_{o}^{2}
$$

With the boundary condition $u_{o}=u_{c}$ for $s=0$, the solution to Eq. (7) is,

$$
u_{o}=u_{c} \exp \left(-k_{f} s\right)
$$

where $u_{c}$ is the velocity of the up-rushing wave at the berm crest (which is equivalent to the velocity at the dune toe, if friction is neglected). The effect of this velocity reduction on $q_{o}$ is quantified by an adjusted run-up height $R^{\prime}$ in Eq. (5) instead of $R$, where $R^{\prime}$ is calculated from:

$$
R^{\prime}=R \exp \left(-2 k_{f} s_{B}\right)+z_{D}\left[1-\exp \left(-2 k_{f} s_{B}\right)\right]
$$

where $s_{B}=y_{B}-y_{D}$. This expression gives a more realistic description than Eq. (5), because it accounts for the reduction in impact as a result of horizontal travel distance of the wave front. 
If $k_{f} \rightarrow 0, R^{\prime} \rightarrow R$, and there is no effect of friction on the run-up height and the impact velocity. On the other hand, if $k_{f} \rightarrow \infty, R^{\prime} \rightarrow z_{D}$ and the run-up only reaches the berm crest, giving an impact velocity of zero. The friction coefficient will be a function of the flow properties and the roughness of the sand surface on the berm (Camenen et al., 2006; 2009), and will in the general case vary across the berm. However, for the schematic approach taken here, the friction coefficient is specified as a constant value. Studies on bore propagation on low-sloping foreshores may give insight to appropriate values on the friction coefficient. Raubenheimer et al. (1995) used a coefficient value of $f=0.008$ in solving the shallow-water equations in the swash. They stated that model simulations were not sensitive to values in the range $0.005<f<0.025$. It is difficult to compare $f$ with $k_{f}$, because $k_{f}$ is dimensional in Eq. (6) and needs to be divided with the local water depth to be consistent with $f$. In the present study a value of $k_{f}=0.02$ was employed, which for a realistic bore height puts the value of $f$ in the lower range of previous investigations.

\section{Coupling between Subaerial Profile Response and Shoreline Change}

The resulting volume change of the dune $\square V_{D}$ and the associated movement of the location of the dune toe $\square y_{D}$ are the combination of transport by wind (constructive) and wave impact (destructive):

$$
\frac{d V_{D}}{d t}=\frac{d V_{D w}}{d t}+\frac{d V_{D o}}{d t}=\left(\frac{d y_{D w}}{d t}+\frac{d y_{D o}}{d t}\right) D_{D}=\frac{d y_{D}}{d t} D_{D}=q_{w}-q_{o}
$$

Thus, if $q_{w}>q_{o}$ the dune will advance, whereas if $q_{w}<q_{o}$ it will recede, and at $q_{w}=q_{o}$ equilibrium occurs. If a volume $\Delta V_{D}$ is added to the dune, the same volume should be taken from the profile over its active depth, which is the sum of the vertical distance from the berm crest $D_{B}$ to the still-water level and the depth of closure $D_{C}$ (see Fig. 1). Under the assumption that dune and beach profile change occur with the same shape, continuity requires that:

$$
\Delta y_{D} D_{D}+\Delta y_{B}\left(D_{B}+D_{C}\right)=0
$$

where $\Delta y_{B}$ is the berm crest translation due to interaction with the dune system. Equation (11) may be re-arranged to yield:

$$
\Delta y_{B}=-\Delta y_{D} \frac{D_{D}}{D_{B}+D_{C}}
$$

This equation provides a simple estimate of the needed profile recession due to cross-shore processes, from the foot of the dune to the depth of closure, to produce a certain dune advance, and vice versa. Next, the cross-shore exchange between the berm and dune is combined with the alongshore sand transport rate caused by obliquely breaking waves through the continuity equation of shoreline change:

$$
\frac{\partial y}{\partial t}=-\frac{1}{D_{B}+D_{C}}\left(\frac{\partial Q}{\partial x}\right)+\frac{\partial y_{B}}{\partial t}=-\frac{1}{D_{B}+D_{C}}\left(\frac{\partial Q}{\partial x}-q_{o}+q_{w}\right)
$$

where the berm translation due to cross-shore interaction between the dune and berm are linearly added to the contribution by the gradient in longshore transport rate, $\partial Q / \partial x$, to obtain the total shoreline response.

\section{ANALYTICAL SOLUTION TO EQUATIONS GOVERNING DUNE PROCESSES}

Based on the theoretical developments and empirical relationships discussed in the previous section, the governing equations for the movement of the dune toe $y_{D}$ and the berm crest $y_{B}$ location are:

$$
\begin{gathered}
\frac{d y_{D}}{d t}=\frac{q_{w}-q_{o}}{D_{D}} \\
\frac{d y_{B}}{d t}=-\frac{q_{w}-q_{o}}{D_{B}+D_{C}}
\end{gathered}
$$


If the expressions for dune growth by wind-blown sand transport and by erosion caused by wave impact are simple, analytical solutions may be developed to solve Eqs. (14) and (15). Such an approach provides insight to the general properties of the governing equations and the time scale controlling the response of the dune and its coupling to the beach. It is not possible to find analytical solutions if the wind-blow sand transport rate is described by Eq. (3). Thus, a simpler form is introduced to proceed with an analytical solution. An equation that exhibits similar properties to Eq. (3), that is, growth in the transport rate with distance from the berm crest towards a maximum value, is:

$$
q_{w}=q_{w o}\left[1-\exp \left(-\alpha\left(y_{B}-y_{D}\right)\right)\right]
$$

where $\alpha$ is a scale coefficient. Erosion by wave impact is described by Eq. (5), assuming that the wave and water level conditions are constant and that energy losses are negligible along the berm.

Combining Eqs. (14) and (15), substituting in Eq. (18) for $q_{w}$, and introducing the variable $w=y_{B}-y_{D}$ (representing the berm width) produces the following equation to solve:

$$
\frac{d w}{d t}=-\frac{q_{w o}}{D_{D}}(1+B)[A-\exp (-\alpha w)]
$$

where $A$ and $B$ are defined by:

$$
\begin{gathered}
A=\frac{q_{w o}-q_{o}}{q_{w o}}=1-\frac{q_{o}}{q_{\text {wo }}} \\
B=\frac{D_{D}}{D_{B}+D_{C}}
\end{gathered}
$$

In deriving the solution to Eq. (17), it is convenient to define the following non-dimensional variable:

$$
\xi=\exp \left[-\alpha\left(y_{B}-y_{D}\right)\right]=\exp (-\alpha w)
$$

The solution to Eq. (17) may be written:

$$
\xi=\frac{A \xi_{o}}{\left(A-\xi_{o}\right) \exp \left(-\alpha A(1+B) q_{w o} t / D_{D}\right)+\xi_{o}}
$$

where

$$
\xi_{o}=\exp \left[-\alpha\left(y_{B o}-y_{D o}\right)\right]=\exp \left(-\alpha w_{o}\right)
$$

and subscript $o$ denotes conditions at $t=0$.

If $t \rightarrow \infty$ in Eq. (21), $\xi \rightarrow A$ for $A>0$, whereas for $A<0$ there is no asymptotic solution, and erosion continues indefinitely. A positive value on $A$ implies that the potential transport rate by wind is larger than the erosion rate due to wave impact ( $q_{w o}>q_{o}$; see Eq. 18), yielding an equilibrium width $w_{e}$ of the berm given by:

$$
w_{e}=\left(y_{B}-y_{D}\right)_{\infty}=\frac{1}{\alpha} \ln \left(\frac{q_{w o}}{q_{w o}-q_{o}}\right)
$$

where the subscript $e$ denotes equilibrium. This expression can also be obtained by setting $d w / d t=0$ in Eq. (17). To display the properties of Eq. (21), the equation is developed and written in nondimensional form according to:

$$
w^{\prime}=\frac{1}{\alpha^{\prime}} \ln \left(\frac{1}{A}\left[1-\left(1-A \exp \left(\alpha^{\prime}\right)\right) \exp \left(-\alpha^{\prime} A B t^{\prime}\right)\right]\right)
$$

where $w^{\prime}=w / w_{o}=\left(y_{B}-y_{D}\right) /\left(y_{B o}-y_{D o}\right), t^{\prime}=q_{w o} t / w_{o} D_{D}$, and $\alpha^{\prime}=\alpha w_{o}$. Fig. 2 illustrates the time evolution of the berm width towards equilibrium for various values on the ratio $q_{o} / q_{w o}$ and $\square{ }^{\prime}=1.0$. The value $B=1 / 3$ represents a dune height $D_{D}$ that is one-third that of $\left(D_{B}+D_{C}\right)$. The initial berm width is 


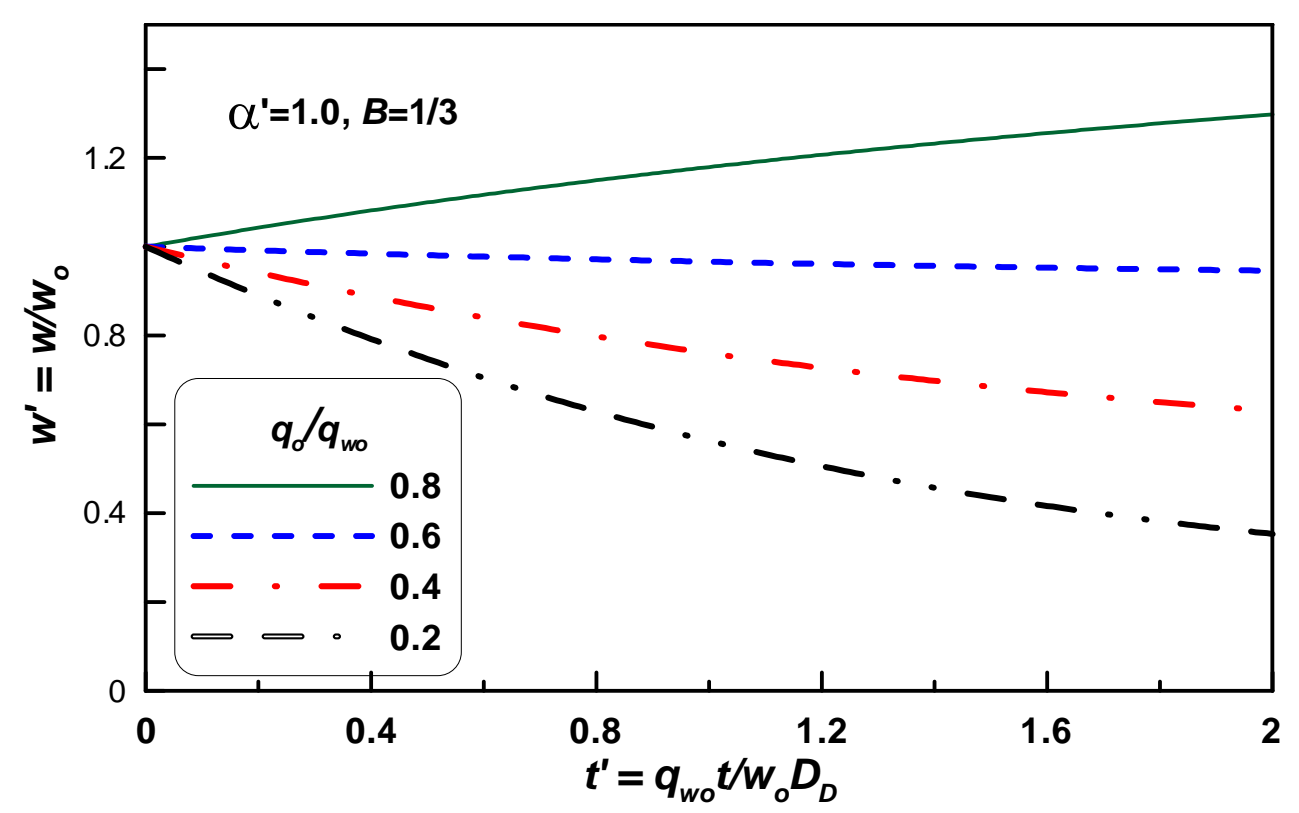

Figure 2. Non-dimensional evolution of the berm width for varying $q_{o} / q_{w_{o}}$-ratios in the case of dune build-up by wind and dune erosion due to wave impact.

shorter than the equilibrium value for the largest $q_{0} / q_{w o}$-ratio, which causes the berm width to increase. Fig. 3 displays calculated evolution of the berm, where $\square^{\prime}=1.0$ and $A=0.6$ (corresponding to $q_{o} / q_{w o}=0.4$ ). A relatively larger active profile height with respect to the dune height causes a slower response towards equilibrium.

With analytical solutions to somewhat simplified versions of the coupled equations demonstrating reasonable results, the governing equations for coupled cross-shore and longshore processes are now solved numerically for a field application.

\section{APPLICATION TO WESTHAMPTON BEACH, LONG ISLAND, NEW YORK}

Westhampton is located on the eastern south shore of Long Island, between Shinnecock Inlet and Moriches Inlet (Fig. 4). The beach is composed of medium sand with a representative median grain size $d_{50}$ of $0.4 \mathrm{~mm}$, and the net average annual rates of longshore sand transport at the site have been variously estimated at $115,000-230,000 \mathrm{~m}^{3} / \mathrm{yr}$ directed to the west, although reversals are typical in the summer and may persist through a particular year (Rosati et al., 1999; Larson et al., 2002a). Long-term wave and water level data were input to the numerical model to calculate dune change, berm change, and shorelines position. Hindcast data from the U.S. Army Corps of Engineers Wave Information Study (WIS) (http://chl.erdc.usace.army.mil/wis) were available from 01/01/76 to 31/12/95 and measured water levels from $01 / 01 / 80$ to $31 / 12 / 00$, both at 3-hr intervals. Thus, the period with simultaneous wave and water level data covered the period 01/01/80 to 31/12/95. Based on examination of a large number of profile surveys along the beach, the average dune height (above the berm) was estimated to be $1.5 \mathrm{~m}$, the average berm elevation $3 \mathrm{~m}$ above MSL, and the average depth of closure $8 \mathrm{~m}$. The transport rate by wind at equilibrium, $q_{\text {wo }}$, was set to $0.0025 \mathrm{~kg} / \mathrm{m} / \mathrm{s}$, based on analysis of the actual dune toe migration on site. This magnitude is in good agreement with the rates presented in Davidson-Arnott and Law (1990), who measured transport by wind across the berm in the field. This transport rate corresponds to a wind speed of slightly more than $6 \mathrm{~m} / \mathrm{s}$.

In the following, two examples based on the general conditions at Westhampton are first given, neglecting the groin field there, to illustrate behavior and trends in the numerical solution. An application of the model is then presented where groin shortening is considered as an engineering alternative for supplying sand to the down-drift (western) beach. 


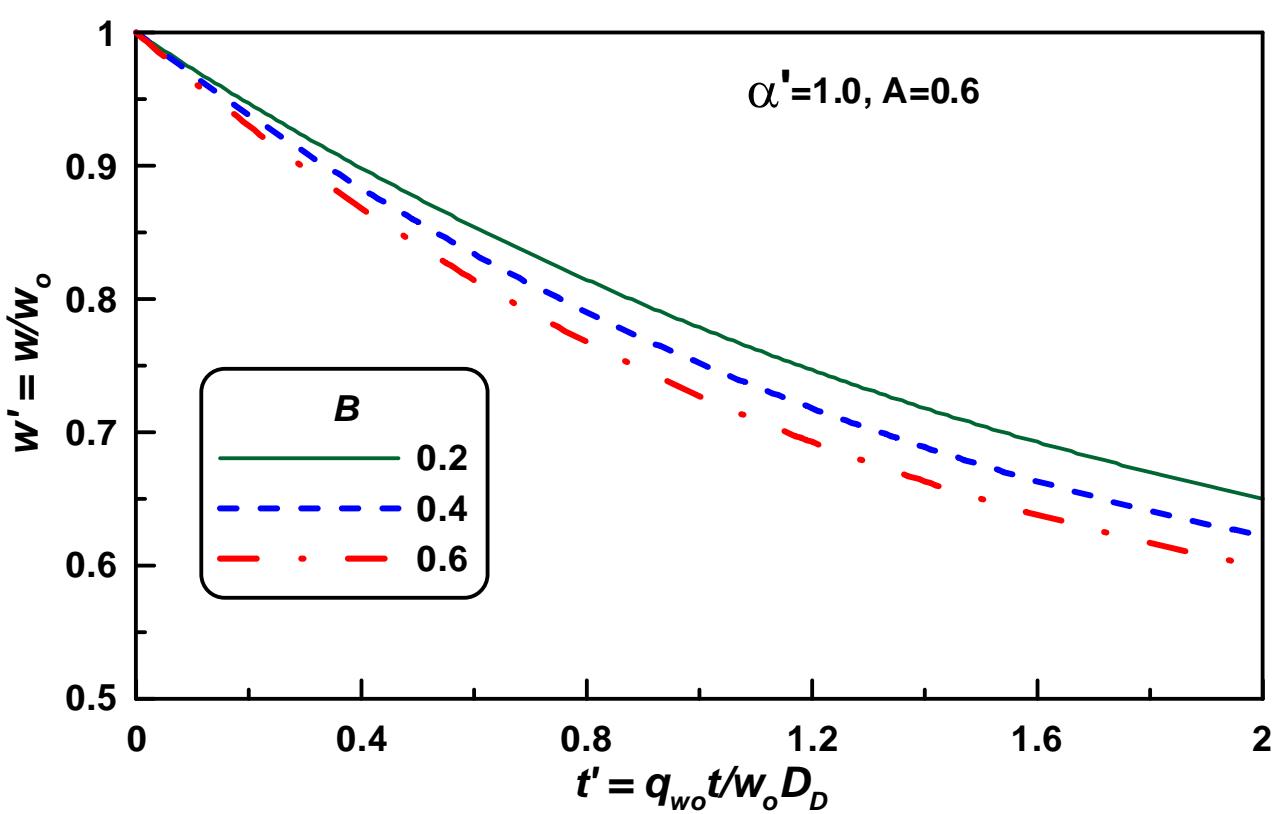

Figure 3. Non-dimensional evolution of the berm width for varying $B$-values in the case of dune build-up by wind and dune erosion due to wave impact.

\section{Beach Change by Cross-Shore Processes Only}

To investigate model coupling between the dune and the shoreline with only cross-shore processes active, several sensitivity tests were run for a 30-year period specifying wave uniformity alongshore. This configuration allows examination of predicted time-varying shoreline and dune foot locations in an arbitrary beach profile. The shoreline (thick solid line in Fig. 5) was initially located $360 \mathrm{~m}$ from the baseline and the dune toe (thin solid line) $280 \mathrm{~m}$ from the same baseline, resulting in an initial berm width of $80 \mathrm{~m}$. This initial berm width was close to the value corresponding to its long-term equilibrium, as indicated by the absence of a clear long-term trend in the shoreline position, although small shoreline fluctuations occur at shorter time scales. Similarly, the location of the dune toe shows no long-term trend. However, location of the dune toe varies more than the shoreline position because the active beach profile height $(8+3 \mathrm{~m})$ is more than seven times larger than the dune height $(1.5 \mathrm{~m})$, c.f. Eq. (12). The calculated shoreline variation is about $6 \mathrm{~m}$ over the simulation period, which is significantly smaller than values observed, probably because wave-induced erosion of the berm is not represented.

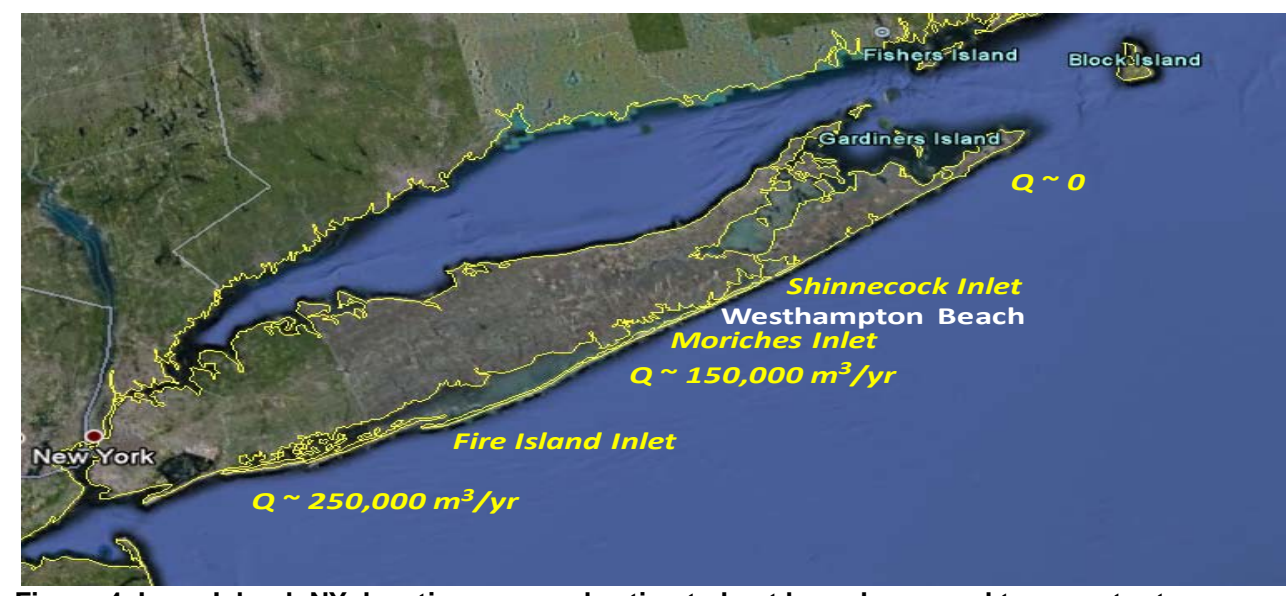

Figure 4. Long Island, NY, location map and estimated net longshore sand transport rates. (map from Google Earth) 


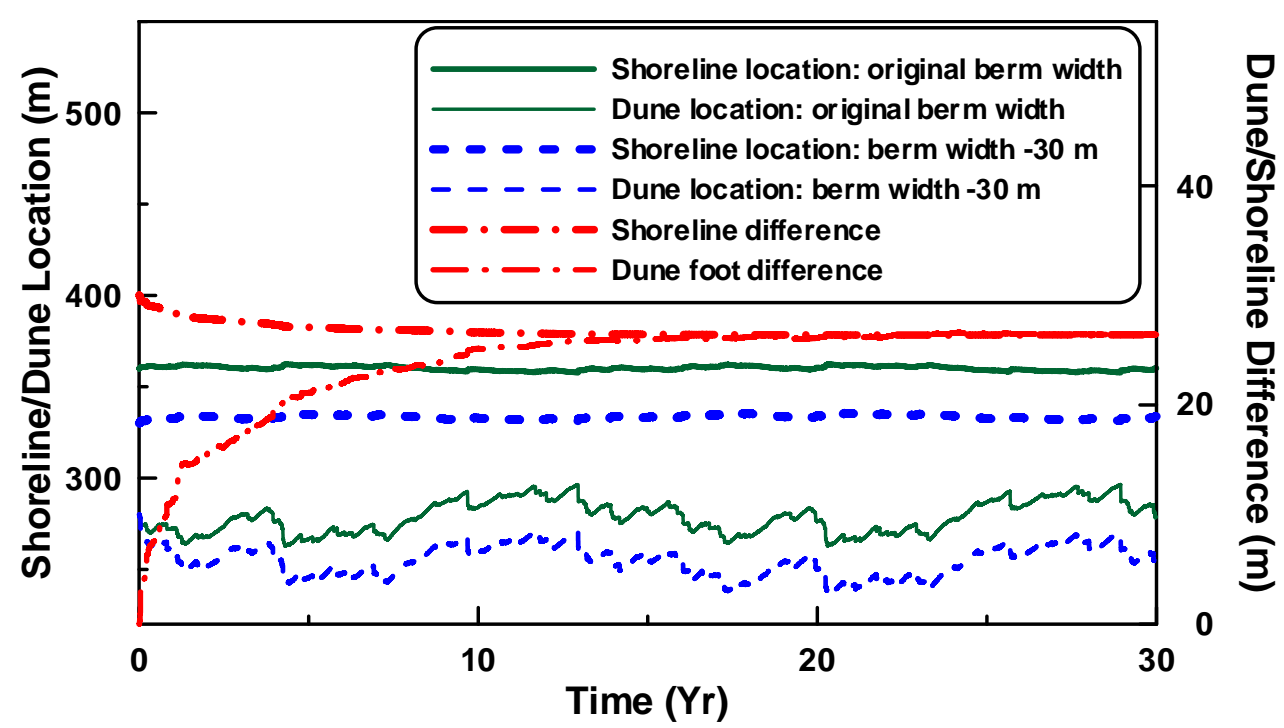

Figure 5. Temporal evolution of shoreline and dune toe location for two sensitivity tests encompassing cross-shore processes only.

In a second configuration, the shoreline (thick dashed line) was set back $30 \mathrm{~m}$, compared to the initial conditions in the first configuration, while leaving the initial dune toe location the same as in the first configuration. The dune (thin dashed line) displays similar short-term fluctuations as in the first configuration, but over the years it gradually recedes slightly more and recovers slightly less compared to the first configuration, attaining its equilibrium position further back. The difference between the dune toe locations for the two configurations is indicated by the thin, dash-dotted line in Fig. 5. Initially, the difference is zero but gradually it increases over the years. After some 22 years, the difference has grown to $26 \mathrm{~m}$, after which it remains virtually constant. Over the same time, the difference in shoreline position (thick, dash-dotted line) decreased from its original $30 \mathrm{~m}$ to the same $26 \mathrm{~m}$ as for the dune. Thus, the beach and dune were re-established in a dynamic equilibrium where the beach and dune have the same relative locations as before the set back of the shoreline. These tests demonstrate that the model of the cross-shore exchange between the beach and the dune produces a long-term dynamic equilibrium balance. If the berm width is perturbed from its equilibrium value, the beach and dune will change accordingly to re-establish a new dynamic equilibrium.

\section{Beach Change by Combined Cross-Shore and Longshore Processes}

To illustrate the interaction between longshore and cross-shore transport processes, an example is given for a straight shoreline and longshore transport generated using the same WIS wave hindcast time series for Westhampton Beach as in the previous example. The simulation covers the 15-year period July 1, 1980 to June 30, 1995. A constant gradient was imposed on the longshore transport such that the beach would erode when the transport direction was positive (to the west) and accrete for negative transport rates. The simulation results are illustrated in Fig. 6, where the shoreline evolution with only longshore processes active is shown as a solid line. The calculated net shoreline change was $7.5 \mathrm{~m}$ corresponding to $0.5 \mathrm{~m} / \mathrm{yr}$, which is a realistic number for many eroding sites along the eastern part of the south shore of Long Island (Rosati et al., 1999). Because cross-shore transport processes were not included in this simulation, the location of the dune toe did not move.

If cross-shore transport is included through wind-blow sand transport and dune erosion, dune volume will vary which, in turn, will induce increasing shoreline fluctuations as material exchange occurs between the dune and the shoreline (Fig. 6, dashed line). The long-term longshore trend is still apparent with a shoreline net change trend of $6.7 \mathrm{~m}$ over the 15 years. As seen from Eq. (12), shoreline and dune toe fluctuations are coupled. For Westhampton Beach, dune height $D_{D}$ is on the average $1.5 \mathrm{~m}$, the berm height $D_{B}$ is $3 \mathrm{~m}$, and the depth of closure $D_{C}$ is $8 \mathrm{~m}$. Thus, dune fluctuation will be scaled as 11/1.5 times the shoreline fluctuations, as seen from the Fig. 6 .

To investigate the role of wave sequencing and wave variability on shoreline change, the same schematic case as above was run for a series of different wave climates. In addition to the original WIS hindcast time series, ten new 15-year time series were constructed by random sampling of individual 


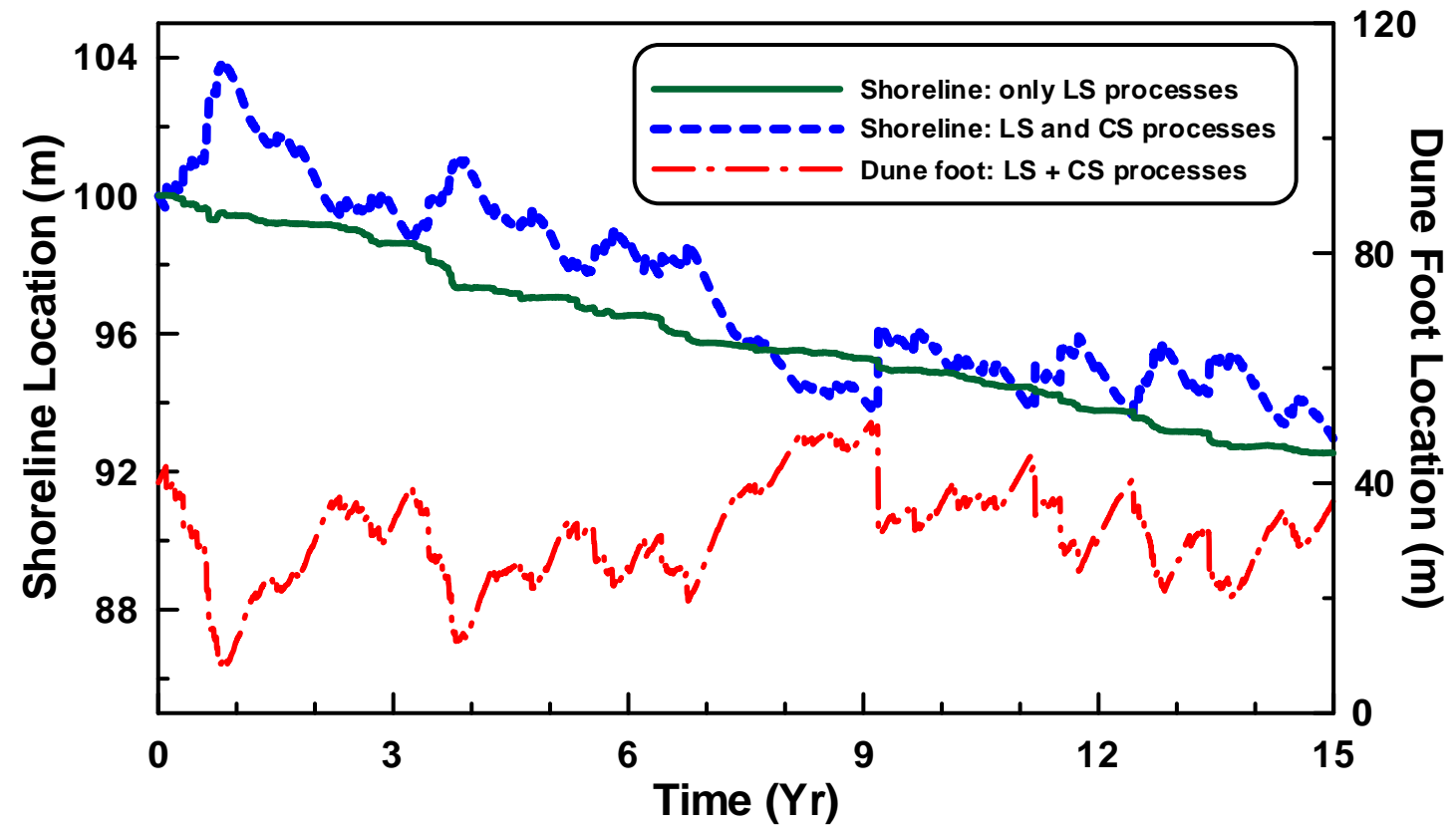

Figure 6. Shoreline change over 15 years with a) only longshore (LS) processes included (solid line), and b) both longshore and cross-shore (CS) processes included (dashed and dash-dotted lines).

years from the original series (by sampling complete years; seasonality, typical annual storm waves, and associated storm water level were maintained). Sampling was done with replacement, so that a specific individual year could be sampled more than once. Fig. 7 displays calculated shoreline evolution for only longshore processes. The thick line represents an average of the 11 individual shoreline locations. For this average shoreline, the net shoreline change over the 15 years was $7.3 \mathrm{~m}$, i.e., close to the change for the original wave time series. The difference in shoreline location after 15 years is $2.3 \mathrm{~m}$ between the run with most net erosion and the one with the least net erosion, corresponding to $32 \%$ of the average change.

Fig. 8 shows the shoreline evolution for the same wave time series, but with cross-shore processes included. There is considerably more variability in shoreline location for each wave climate as well as between wave climates, because of cross-shore exchange of material between the dune and the

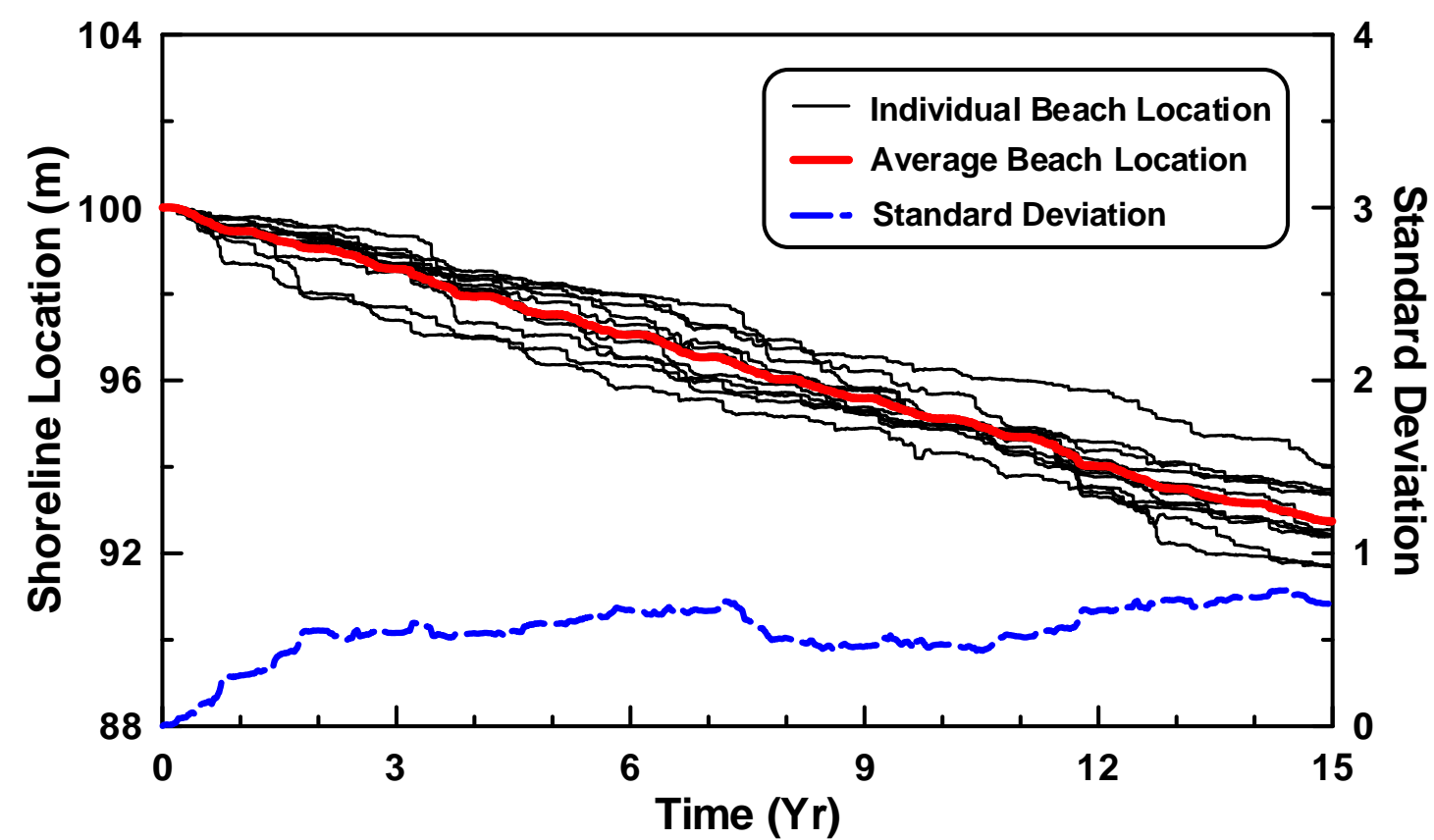

Figure 7. Shoreline change caused by longshore processes only over 15 years for 11 different wave climates. The thick line represents an average of the 11 individual shoreline locations. 


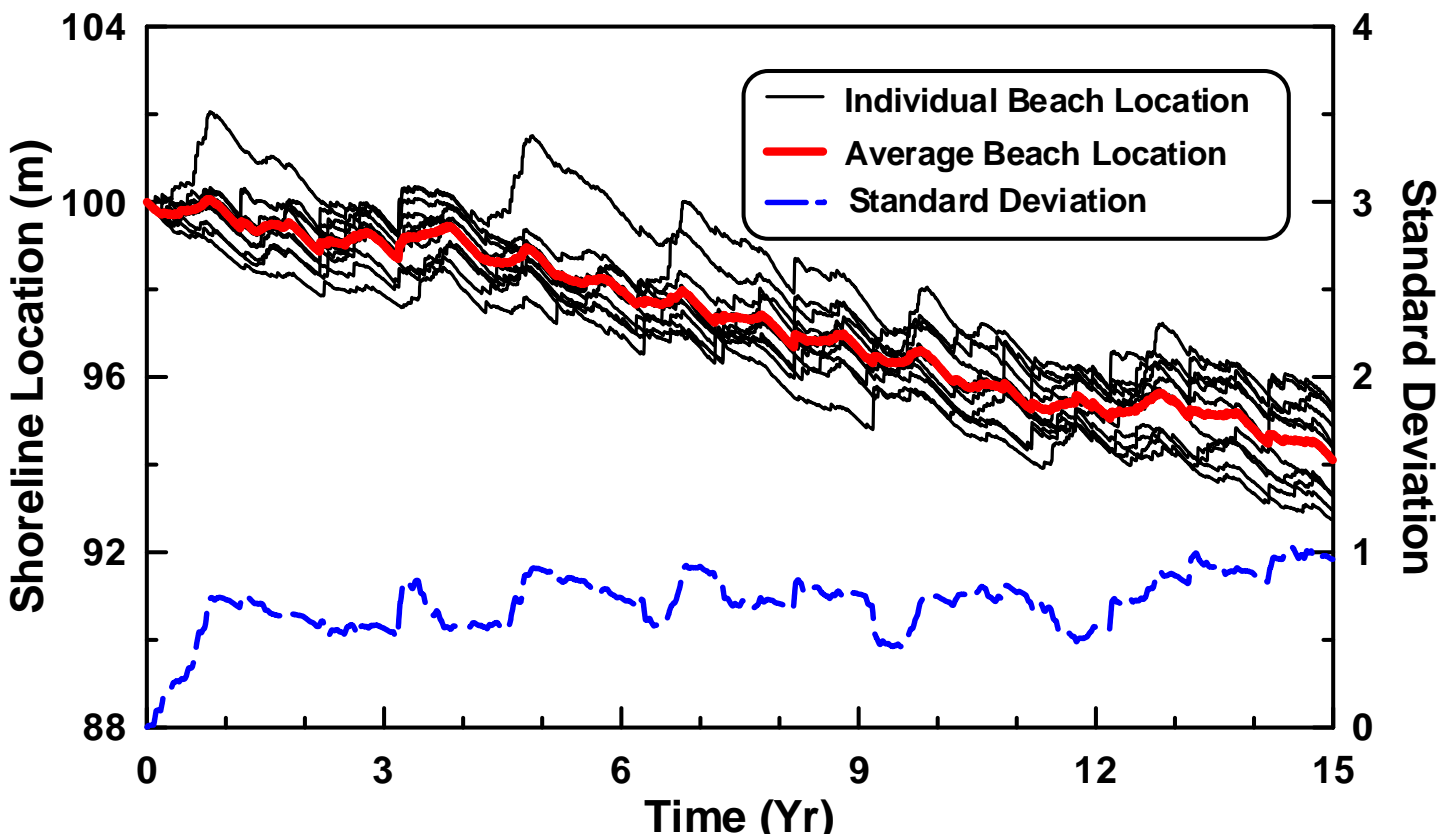

Figure 8. Shoreline change caused by combined longshore and cross-shore processes over 15 years for 11 different wave climates. The thick line represents an average of the $\mathbf{1 1}$ individual shoreline locations.

shoreline. For the average shoreline, the net shoreline change over the 15 years was $5.9 \mathrm{~m}$, slightly less than for longshore processes alone, because dune erosion supplies more sand to the berm, than the longshore gradient in transport is able to remove. At the same time, the difference in shoreline location after 15 years is as much as $2.4 \mathrm{~m}$ between the run with most net erosion and the one with the least net erosion, corresponding to $41 \%$ of the average change.

From a coastal management point of view, variability in shoreline location about some mean must be considered (Smith and Kraus, 1999). For determining the location of housing and infrastructure development, the shoreward-most position of the shoreline over some period of time with some suitable set back might be of primary interest, whereas in considering potential bypassing around coastal inlets and their jetties, the seaward-most location might be of interest. Thus, to represent these changes on different time scales, long-term and short-term processes must be combined in a modeling system, where the former is more closely related to longshore transport and transport by wind, and the latter to episodic cross-shore transport that may occur during storms and elevated water level.

Another issue with relevance for global climate change is the sensitivity of shoreline evolution to changes in wave height. To investigate how the model responds to variations in wave height, runs were made over 15 years with seven different wave climates, keeping the water level constant. In addition to the original wave time series, six new time series were constructed by increasing the offshore wave height 10, 20, and 30\%, respectively, and by reducing the wave height with the same percentage (Fig. 9). After about 1 year, a storm with larger waves occurs, inducing dune erosion that produces significant shoreline advance. Longshore transport gradients cannot keep pace with (remove) the supply of sand from the dunes initially, but gradually longshore transport erodes the beach. In fact, the erosion caused by longshore transport will eventually be larger for the higher waves. Thus, the effect of increased sand supply from the dunes to the berm system will disappears after about 9 years.

Subsequently, the beach is struck by another large storm. However, this time the wave climate with the smaller waves (dash-dot lines) will induce greater change than the more severe wave climate (dashed lines) indicated by a larger vertical displacement of the dash-dot lines. The explanation is that due to larger sand losses from the dune by greater cross-shore transport for the larger waves, the system contains less sand available for transport in the large wave cases. Thus, even though the shoreline locations coincide, the dune toe location is further landward for the larger waves and higher water levels. In spite of the waves and the associated run-up being larger, wave impact on the dune becomes smaller from the larger waves because the dune toe is located further landward. This response of the dune and the shoreline illustrates the complexity of the system and the significant role of sequencing regarding the forcing. 


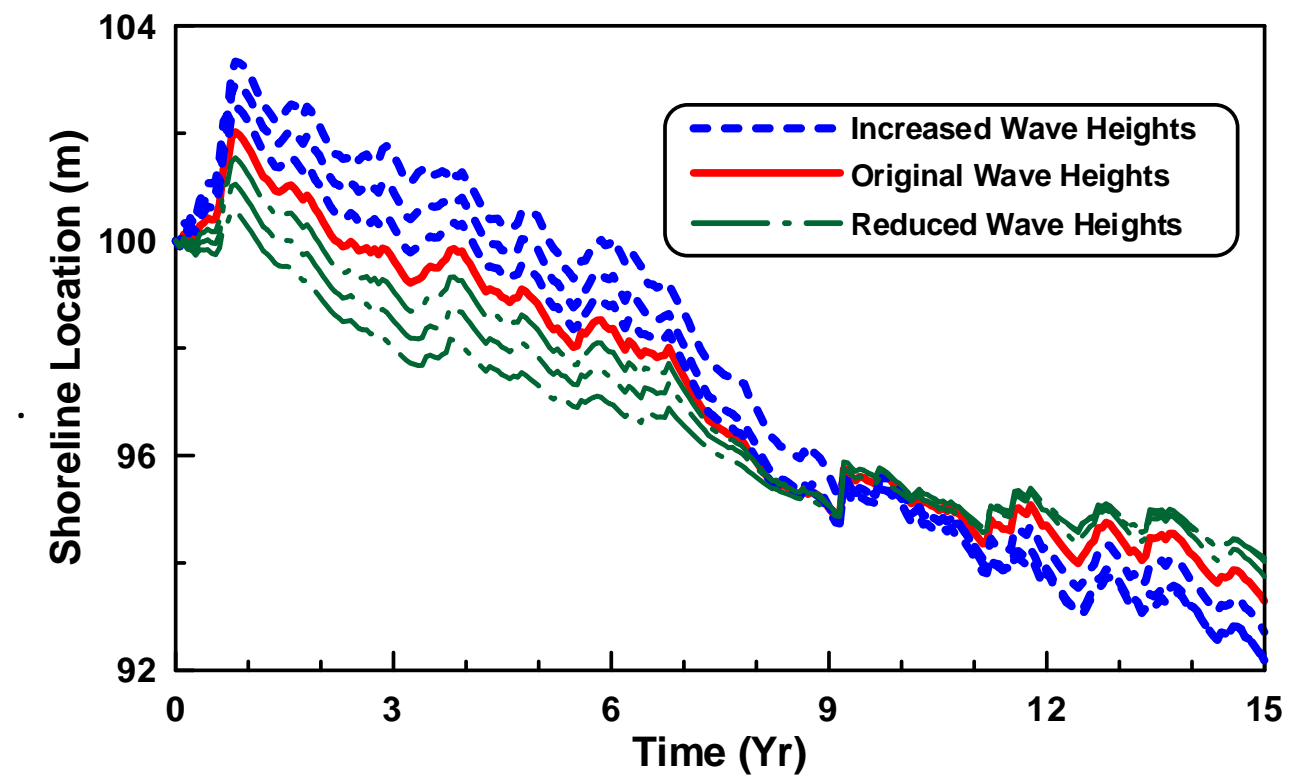

Figur 9. Shoreline change caused by combined longshore and cross-shore processes. Runs were made over 15 years using 7 different wave climates. In addition to the original WIS time series, 6 new time series were constructed by increasing the offshore wave height 10, 20, and $30 \%$ (thick blue, dashed lines), respectively and by reducing the wave height with the same percentage (thin green.dash-dotted lines).

\section{Evaluation of Groin Shortening}

There are presently 16 groins at Westhampton Beach. The first eleven and easternmost (up-drift) groins were constructed over 1965-1966 in response to breaching during the March 1962 northeaster. Four additional groins were constructed to the west during 1969-1970. The rubble stone groins in this field of 15 structures were nominally $146 \mathrm{~m}$ long, tapering to the sea bottom and having spacing of approximately $365 \mathrm{~m}$. Kraus and Batten (2006) provide the most recent summary of groin configuration and functioning at Westhampton Beach.

The original groins functioned as intended (Nersesian et al., 1992) in protecting a once-vulnerable 5-km long segment of barrier beach that had experienced breaching during the September 1938 Great New England Hurricane, a 1958 storm, and the March 1962 northeaster. Although the ten groin compartments of the eleven original groins were not filled during initial construction, natural longshore transport eventually accomplished this. Over the years onshore-directed wind-blown sand has created a high and broad dune that is fronted by a wide berm. Beach fill accompanied construction of Groins 1215. In December 1992, a northeaster opened two inlets (called Pikes Inlet and Little Pikes Inlet) directly west of the groin field. Pikes Inlet, located most westward, gradually shoaled and was readily closed manually (Bocamazo and Grosskopf, 1999), but Little Pikes Inlet enlarged in the eroding downdrift area directly west of Groin 15. In 1993, the U.S. Army Engineer District, New York (NYD) closed the breach by hydraulic fill placement. In 1996-1997, a tapered groin transition to the west was created by shortening Groins 14 and 15 and adding a short groin (called Groin 14A) between them. The groin tapering together with beach fill has been successful, and the planned renourishment of 3 years has been extended to 4 years.

As an alternative to the existing condition, the NYD considered shortening of groins in the eastern and middle portions of the groin field and tapering of the groins on the western end, together with continued renourishment. Groin shortening may be a cost-effective solution as compared to beach nourishment from an external source for maintenance of the beach west of the groin field, at least for a certain length of time until the beach and dune in the groin compartments develop equilibrium with the modified structures. Shortening of the groins has the potential for gradually releasing sand to the littoral system as the shoreline and dune line recede. If the beach is in equilibrium with the groin field, a reduction in groin length is expected to lead to recession of the shoreline and dune as the beach is reaching a new equilibrium. In conclusion, the dune and berm (as represented by shoreline position) are expected to recede if the groins are shortened. The time scale of this process is not known a priori and is an output from the application of the new model.

Calibration. The model was set to match the annual net longshore transport rate at the site, following the procedure described by Kraus et al. (1994). The coefficients for sand transport to and 
from the dune were set based on the experience from the cross-shore test described in the previous section. Simultaneous wave and water level data (from the Sand Hook, New Jersey, long-term tide station) were input to the model to calculate long-time dune and beach berm change. Simultaneous waves and water level (including storm surges) at 3-hr interval are available from 1 January 1980 to 31 December 1995. These data served in the calibration process, for which the measured shoreline positions of 1972 and 1983 were used. The result of the calibration is shown in Fig. 10.

Starting with the measured 1972 shoreline (short-dashed line), the main features of the measured 1983 shoreline (long-dashed line) were reproduced (solid line). In particular, the continued accretion on the up-drift side of the groin field is replicated, as well as the accretion in the eastern and central sections of the groin field and the erosion in the western section. The model also predicted the amount of down-drift erosion well; however, it is located too close to the groin field. The mean calculated transport rate alongshore was about $400,000 \mathrm{~m}^{3} / \mathrm{yr}$, which is greater than the long-term average estimated value. Overall, the calibration was judged to be satisfactory.

Response to Groin Shortening. To quantify the response of the dune and beach to groin shortening, the model was run for 20 years for two groin length alternatives, one with the original lengths as described above and one where the groin lengths were reduced by $30 \mathrm{~m}$. Both simulations started with the measured 1995 shoreline and included the beach fills that were reported to be added in 1996-1997. During initial construction in 1996 and 1997, about 2.7 million $\mathrm{m}^{3}$ of sand dredged from an offshore borrow site was placed from Groin 7 to approximately 3,000 m down drift (west) of Groin 15. For the simulations, the fill was divided, with 1.1 million $\mathrm{m}^{3}$ within the groin field and 1.6 million $\mathrm{m}^{3}$ distributed to the west of Groin 15. The beach section consisted of a berm $2.9 \mathrm{~m}$ above MSL and about $27 \mathrm{~m}$ wide.

Fig. 11 (long-dashed line) shows the result of the 20-year simulation with the original groin lengths. As expected, accumulation continues up drift of the groin field and also somewhat inside the western part of the groin field. Erosion occurs in the last groin compartment and down drift of the groins. The result of the second simulation, with the shorter groins, is shown as a solid line in Fig. 11. There is a notable difference as compared to the results for the original groin lengths. Shoreline advance (accretion) up drift of the groin field and inside the western side of the groin field was substantially reduced. Likewise, the significant recession in the easternmost two groin compartments and down drift of the groin field was also substantially reduced. The reduced down-drift erosion of $410,000 \mathrm{~m}^{3}$ is still only slightly more than half or the estimated potential of $750,000 \mathrm{~m}^{3}$, which would correspond to a situation where the entire beach and dune system would move back the same distance as the groin shortening, i.e., $30 \mathrm{~m}$. Thus, it is estimated that the sand supply from the groin length reduction will persist for at least 30 years.

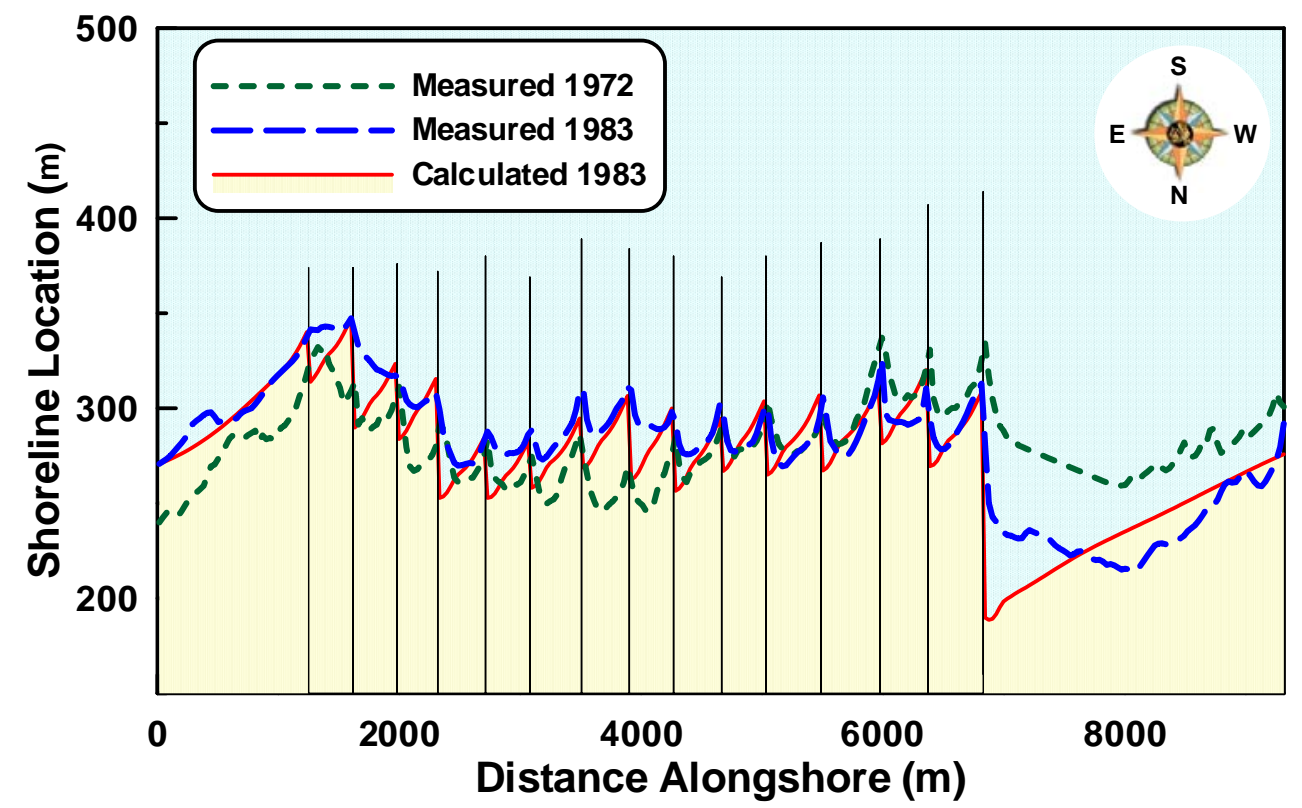

Figure 10. Calibration run for Westhampton Beach. Simulation from 1972 to 1983. 
This simulation indicates that the beach and dune at Westhampton Beach will recede up drift and inside the groin field and that the down-drift beach will accrete in response to groin shortening. It will, however, take several decades before the down-drift beach receives the full benefit of the groin length reduction and before a new equilibrium condition is established.

\section{CONCLUSIONS}

A new numerical model has been presented for calculating beach and dune change under combined cross-shore and longshore transport processes. Predicting this change involves coupling among the dune, berm, and shoreline, and it describes the beach as a balance of dune growth by windblown sand, dune destruction during storms, change in berm width (which enters in providing the surface for sand to be blown), and gradients in wave-induced longshore transport. Equilibrium morphologic concepts were included to improve model predictive reliability and stability of calculations with the coupled non-linear equations. Simplification of the governing equations and boundary conditions allowed analytic solutions to be obtained for examining model properties and performance.

Sensitivity tests with the numerical model revealed that berm width plays a central and, perhaps, subtle role in protecting the dune against storms through its storage mechanism. The sensitivity tests also examined the role of increased wave height in storms as a possible consequence of global warming. A coastal management conclusion is that higher volume dunes can protect the coast even for higher waves.

Finally, an engineering application of the coupled cross-shore and longshore transport processes model was made for evaluating groin shortening. Prior to development of this model, there was no technology available to calculate the time scale of combined beach and dune change, or the long-term interaction of the beach and dunes. A conclusion of the case study was that groin shortening would function in providing the desired up-drift feeder beach, and the sand would be released over several decades in a gradual process of adjusting to the new structure lengths.

This study has brought to light many interesting morphologic questions and focused them within a quantitative calculation framework. For example, is there an equilibrium berm width for given beach sediment grain size, transport rate by wind, and frequency of storms? Such questions can now be pursued for improving engineering calculations of beach and dune change under realistic conditions.

Major processes presently lacking that are planned to be introduced to the model is cross-shore sub-aqueous transport by wave action and by wave overtopping and overwash of the dunes. These further developments are under way and will be operational in the near future.

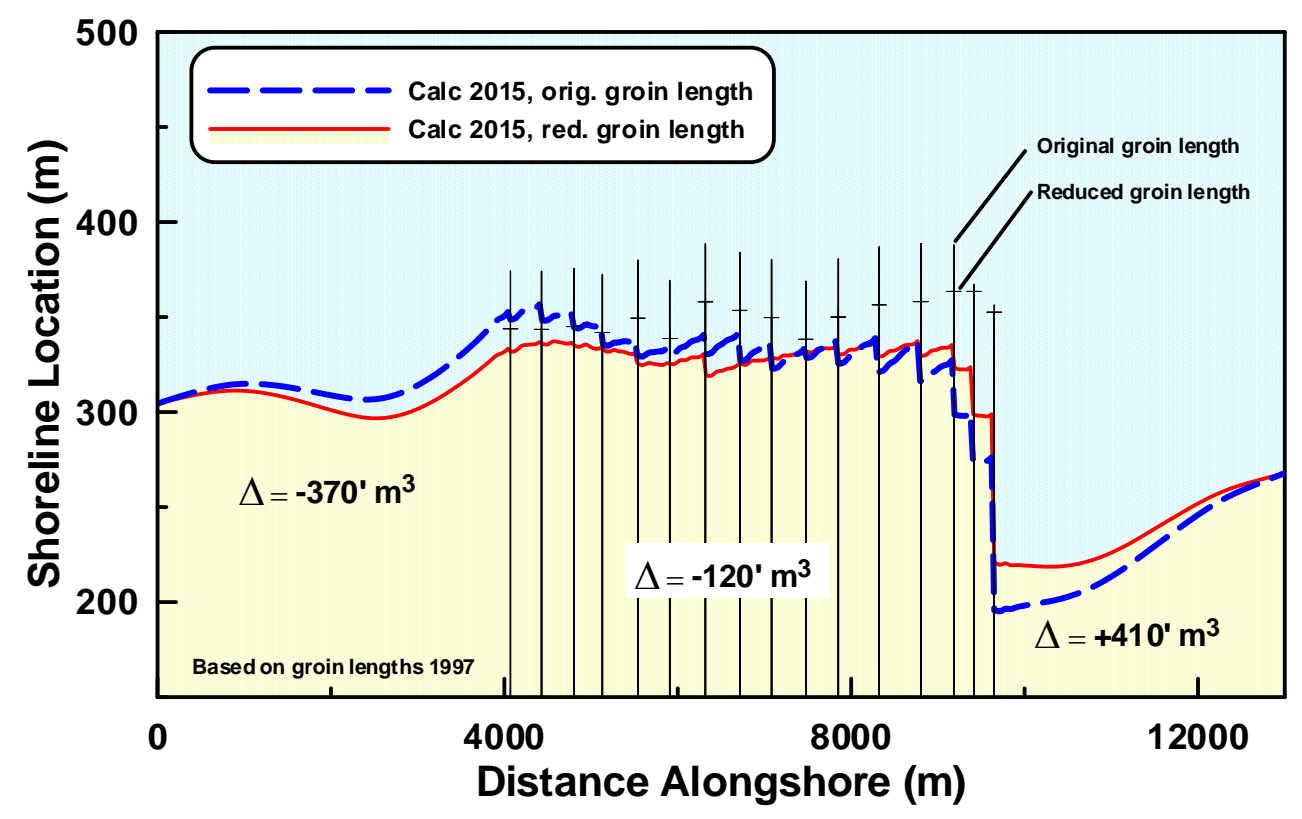

Figure 11. Calculated shoreline change at Westhampton Beach over 20 years with existing groins and with reduced groin lengths. Numbers indicate difference in volume updrift, inside, and downdrift the groin field, respectively, between the two scenarios. 


\section{ACKNOWLEDGMENTS}

This work was supported by the U.S. Army Corps of Engineers Regional Sediment Management Program, through funding to the U.S. Army Engineer District, New York, and as part of activities of the Coastal Inlets Research Program and the System-Wide Water Resources Program. The guidance of Lynn M. Bocamazo, Senior Coastal Engineer, at the New York District is greatly appreciated. Permission was granted by Headquarters, U.S. Army Corps of Engineers, to publish this information.

\section{REFERENCES}

Bagnold, R. A. 1954. The physics of blown sand and desert dunes, Methuen \& Co. Ltd., London, 265 pp.

Bocamazo, L.M., and Grosskopf, W.G. 1999. Shore response to groins, Westhampton, New York. Proceedings Coastal Sediments '99, ASCE, 2,073-2,089.

Camenen, B., Bayram, A., and Larson, M. 2006. Equivalent roughness height for plane bed under steady flow, Journal of Hydraulic Engineering, 132(11), 1146-1158.

Camenen, B., Larson, M., and Bayram, A. 2009. Equivalent roughness height for plane bed oscillatory flow, Estuarine, Coastal, and Shelf Science, 81, 409-422.

Davidson-Arnott, R.G.D. and Law, M.N. 1990. Seasonal pattern and controls on sediment supply to coastal foredunes, Long Point, Lake Erie, In: Nordstrom, K.F., Psuty, N.P., Carter, R.W.G., (Eds.), Coastal Dunes: Form and Processes, John Wiley \& Sons, 177-200.

Davidson-Arnott, R.G.D., MacQuarrie, K., and Aagaard, T. 2005. The effect of wind gusts, moisture content and fetch length on sand transport on a beach, Geomorphology, 68, 115-129.

Dean, R.G., 1977. Equilibrium beach profiles: U.S. Atlantic and Gulf coasts. Department of Civil Engineering, Ocean Engineering Report No. 12, University of Delaware, Newark, DE.

Erikson, L., Larson, M., and Hanson, H. 2005. Prediction of swash motion and run-up including the effects of swash interaction, Coastal Engineering, 52, 285-302.

Hanson, H. 1989. GENESIS - A generalized shoreline change numerical model, Journal of Coastal Research, 5(1), 1-27.

Hanson, H., and Kraus, N. C. 1989. GENESIS: Generalized Model for Simulating Shoreline Change. Report 1: Technical Reference, Technical Report CERC-89-19, U.S. Army Engineer Waterways Experiment Station, Coastal Engineering Research Center, Vicksburg, MS.

Hopf, F., and Sherman, D.J. 2007. Aeolian processes, coastal dunes, and the Coastal Engineering Manual Part III, Chapter 4 "Wind-Blown Sediment Transport.” Proceedings Coastal Sediments '07, ASCE, 1,241-1,254.

Hotta, S. 1984. Wind blown sand on beaches. PhD dissertation. Tokyo, Japan: Department of Civil Engineering, University of Tokyo.

Kraus, N.C., and Batten, B.K. 2006. Shoreline evolution in a groin field by Reservoir Model approach. Proceedings 30th Coastal Engineering Conference, World Scientific Press, 3,886-3,898.

Kraus, N.C., Hanson, H., and Blomgren, S. 1994. Modern functional design of groins. Proceedings 24th Coastal Engineering Conference, ASCE, 1327-1342.

Larson, M., Erikson, L., and Hanson, H. 2004. An analytical model to predict dune erosion due to wave impact, Coastal Engineering, 51, 675-696.

Larson, M. and Kraus, N.C. 1989. SBEACH: Numerical model for simulating storm-induced beach change, Report 1: Empirical foundation and model development, TR CERC-89-9, U.S. Army Engineer Waterways Experiment Station, Coastal Engineering Research Center, Vicksburg, MS.

Larson, M., and Kraus, N.C. 1991. Mathematical modeling of the fate of beach fill. In: Niemayer, H.D van Overeem, J., and van de Graaff, J. (eds.), Artificial Beach Nourishments, Coastal Engineering, Special Issue 16, 83-114.

Larson, M., Kraus, N.C., and Hanson, H. 2002a. Simulation of regional longshore sediment transport and coastal evolution - The Cascade model, Proceedings 28th Coastal Engineering Conference, ASCE, 2612-2624.

Larson, M., Rosati, J.D., and Kraus, N.C., 2002b. Overview of regional coastal processes and controls. Coastal and Hydraulics Engineering Technical Note CHETN XIV-4, U.S. Army Engineer Research and Development Center, Vicksburg, MS.

Nersesian, G.K., Kraus, N.C., and Carson, F.C. 1992. Functioning of groins at Westhampton Beach, Long Island, New York. Proceedings $23^{\text {rd }}$ Coastal Engineering Conference, ASCE, 3,357-3,370.

Psuty, N. P. 1990. Foredune mobility and stability, Fire Island, New York. In: Nordstrom, K.F., Psuty, N.P., and Carter, R.W.G. (eds.) Coastal Dunes: Form and Process, John Wiley and Sons, NY, $159-200$ 
Raubenheimer, B., Guza, R.T., Elgar, S., and Kobayashi, N. 1995. Swash on a gently sloping beach, Journal of Geophysical Research, 100, 8,751-8,760.

Rosati, J.D., Gravens, M.B., and Smith, W.G. 1999. Regional sand budget for Fire Island to Montauk Point, New York, USA. Proceedings Coastal Sediments '99, ASCE, 802-817.

Smith, S.J. and Kraus, N.C. 1999. Mitigation of a beach-fill hot spot, Monmouth Beach, New Jersey. Proceedings Coastal Sediments '99, ASCE, 2,102-2,117. 